\title{
Involvement of the P1 Cistron in Overcoming elF4E-Mediated Recessive Resistance Against Clover yellow vein virus in Pea
}

\author{
Kenji S. Nakahara, Ryoko Shimada, Sun-Hee Choi, Haruko Yamamoto, Jun Shao, and Ichiro Uyeda \\ Pathogen-Plant Interactions Group, Plant Breeding Science, Research Faculty of Agriculture, Hokkaido University, \\ Sapporo 060-8589, Japan
}

Submitted 2 December 2009. Accepted 12 July 2010.

Two recessive genes (cyv1 and cyv2) are known to confer resistance against Clover yellow vein virus (CIYVV) in pea. cyv2 has recently been revealed to encode eukaryotic translation initiation factor $4 \mathrm{E}$ (eIF4E) and is the same allele as sbml and wlm against other potyviruses. Although mechanical inoculation with crude sap is rarely able to cause infection of a cyv2 pea, biolistic inoculation of the infectious CIYVV cDNA clone does. At the infection foci, the breaking virus frequently emerges, resulting in systemic infection. Here, a derived cleaved-amplified polymorphic sequence analysis showed that the breakings were associated with a single nonsynonymous mutation on the CIYVV genome, corresponding to an amino-acid substitution at position 24 (isoleucine to valine) on the P1 cistron. CIYVV with the point mutation was able to break the resistance. This is a first report demonstrating that $P 1$ is involved in eIF4Emediated recessive resistance.

Recessive genes that confer resistance to viruses have been identified and widely used for crop protection (Diaz-Pendon et al. 2004). In addition to the applied use, identification and analysis of these recessive genes would help us to understand molecular mechanism of viral infection, as most recessive mutations that render hosts nonpermissive to viral infection affect specific cellular factors required for the virus to complete its infection cycle. Although many host factors are expected to be required for plant virus infection according to analyses of plant virus-yeast systems (Kushner et al. 2003; Nagy 2008), only a limited number of host plant factors have so far been identified (Ritzenthaler 2005). In natural crops, eukaryotic translation initiation factor 4E (eIF4E), its isoform eIF(iso)4E, and eIF(iso) $4 \mathrm{G}$ are the only recessive resistance genes identified so far (Albar et al. 2006; Robaglia and Caranta 2006).

Virus strains overcoming recessive resistance have been identified. Mapping analysis of genes of the resistance-breaking (RB) strains, in turn, enables us to identify viral genes corresponding to the recessive resistance genes. It is tempting to assume function of the recessive resistance genes in viral infection from function of the corresponding viral genes and vice versa. Most of eIF4E- and eIF(iso)4E-mediated recessive resistance were reported to be against potyvirus and bymovi-

Corresponding author: K. S. Nakahara; Telephone: +81-11-706-2490; Fax: +81-11-706-2483; E-mail: knakahar@res.agr.hokudai.ac.jp

* The $\boldsymbol{e}$-Xtra logo stands for "electronic extra" and indicates that three supplementary figures and one supplementary table are published online. rus, whose $5^{\prime}$ ends on viral genomes were linked to a genomelinked virus protein $(\mathrm{VPg})$, though some were against cucumovirus, carmovirus, and tombusvirus, whose $5^{\prime}$ ends were capped (Robaglia and Caranta 2006; Yoshii et al. 2004). In most cases, breaking of recessive resistance has been associated with mutations in the VPg cistron (Ayme et al. 2007; Hebrard et al. 2006; Masuta et al. 1999; Moury et al. 2004; Sato et al. 2003). Interaction between VPg and eIF4E or eIF(iso)4E has been consistently demonstrated biochemically and genetically (Beauchemin et al. 2007; Charron et al. 2008; Wittmann et al. 1997). The binding is essential for potyviral infection (Leonard et al. 2000). The resistant phenotypes arose from disruption of the binding of VPg-eIF4E and $\mathrm{VPg}$ eIF(iso)4E by a few mutations in eIF4E and eIF(iso)4E (Kang et al. 2005), and the critical single mutation in eIF4E for binding with VPg has recently been identified (Yeam et al. 2007). Moreover, some mutant VPg in the RB virus have been shown to restore binding with eIF4E protein of the resistance allele, suggesting a coevolutionary arms race between eIF4E and VPg (Charron et al. 2008). Nevertheless, the existence of exceptions to the correlation between the resistant phenotype and the binding eIF4E-VPg (Gao et al. 2004b; Kang et al. 2005) tell us that VPg is not the sole determinant of viral pathogenicity in eIF4E-mediated resistant plants. Indeed, cylindrical inclusion (CI) protein of Lettuce mosaic virus (LMV) was recently reported to be involved in the breaking of an eIF4E-mediated resistance (Abdul-Razzak et al. 2009).

In pea (Pisum sativum), recessive resistance genes to several potyviruses have been mapped genetically to linkage groups II and VI (Provvidenti et al. 1991). The genes that map to linkage group II and control resistance to Clover yellow vein virus (ClYVV, cyv1), Bean common mosaic virus (bcm), Bean yellow mosaic virus (BYMV, mo), Watermelon mosaic virus 2 (mo), Pea mosaic virus (pmv), and Pea seed-borne mosaic virus (PSbMV, sbm2) have not been identified. However, the genes that map to linkage group VI and control resistance to CIYVV (cyv2), PSbMV (sbml), and the white lupin strain of BYMV (BYMV-W, wlm) proved to be the same allele of the eIF4E gene (Andrade et al. 2009; Bruun-Rasmussen et al. 2007; Gao et al. 2004a and b). Analysis of RB by PSbMV and BYMV-W predictably identified their VPg as the pathogenicity determinant (Bruun-Rasmussen et al. 2007; Hjulsager et al. 2002). Here, however, we prove that the P1 protein of ClYVV is the pathogenicity determinant in the RB.

Although P1 function remains unclear, several reports have suggested some functions. The P1 protein is a serine-type proteinase that catalyzes autoproteolytic cleavage at a Tyr-Ser dipeptide between itself and the helper component proteinase 
(HC-Pro) (Rodriguez-Cerezo and Shaw 1991; Verchot et al. 1991, 1992; Yang et al. 1998). The cleavage is required for viral infectivity (Moreno et al. 1998, 1999; Verchot and Carrington 1995b). No other functional domains in P1 are known, but P1 localizes to a cytoplasmic inclusion (Arbatova et al. 1998). P1 protein exhibits nonspecific RNA-binding activity (Brantley and Hunt 1993; Soumounou and Laliberte 1994). In trans, P1 enhances HC-Pro-mediated suppression of RNA silencing (Kasschau and Carrington 1998; Pruss et al. 1997), although P1 itself does not suppress RNA silencing (Anandalakshmi et al. 1998; Brigneti et al. 1998; Hou and Qiu 2003). The enhancing effect on the silencing suppression may explain an accessory function of P1 to stimulate viral multiplication (Verchot and Carrington 1995a and b). P1 protein has also been shown to interact with the cytochrome b6/f complex Rieske Fe/S proteins of host and nonhost plants (Shi et al. 2007). Mutations in the P1 gene change the virulence of LMV of some lettuce cultivars (Krause-Sakate et al. 2005). In the present study, a single mutation in the P1 gene was shown to restore compatibility of CIYVV with the recessive resistant $c y v 2$ pea line, rendered by mutations in eIF4E.

$\mathrm{P} 1$ is the most variable potyvirus protein in both sequence and length (Adams et al. 2005), and it is thought that P1 diversification has contributed to the successful adaptation of potyviruses to a wide range of host species (Valli et al. 2007). This study provides an example in support of this suggestion.

\section{RESULTS}

VPg is not the determinant of pathogenicity in RB by CIYVV/37Brsh in cyv2 pea.

The RB ClYVV isolates in $c y v 2$ pea (CIYVV/37Brsh) were previously obtained and preliminarily characterized (Andrade et al. 2007), and part of the previous study regarding the RB ClYVV isolates in cyv2 pea is summarized here (Figs. 1 and
2A). Biolistic inoculation of the green fluorescent protein (GFP)-tagged infectious plasmid clone pCIYVV/C3-S65T caused infection in cyv2 pea, although conventional mechanical inoculation of crude sap from ClYVV-infected leaves failed to do so. According to the GFP signal (Fig. 2A), as a marker for viral infection, progeny of the virus were isolated by individually cutting out infection foci and, then, propagating them once in inoculated broad bean. Then, each isolate was tested to find whether the viral culture included ClYVV/37Brsh, by using mechanical inoculation to cyv2 pea PI 378195. Sixteen of 18 isolates were able to infect systemically, indicating that most foci generated ClYVV/37Brsh. However, the systemic infection was delayed compared with that in a susceptible pea. Milder mosaic-type symptoms also appeared in PI 378159 with ClYVV/37Brsh. Delayed systemic infection and milder symptoms were shared among isolates derived from the infection foci in PI 378159.

Thus, in this study, we picked up one of the isolates (ClYVV/37Brsh isolate 3, ClYVV/37Brsh-3) propagated in PI 378159 resistant pea to determine differences in nucleotide sequence of its genome with that of its parental ClYVV/C3-S65T. Only one nonsynonymous substitution existed in the P1 cistron (Fig. 1). Previous studies demonstrated that, so far, the pathogenicity determinant of RB viruses in eIF4E- and eIF(iso)4Emediated resistant plants have been exclusively mapped to the VPg cistron, except for one recent report (CI cistron) (AbdulRazzak et al. 2009). However, no difference exists between ClYVV/37Brsh-3 and its parental ClYVV/C3-S65T in the rest of the open reading frame (ORF), including the VPg and CI cistrons.

\section{A single mutation in the P1 cistron of CIYVV/37Brsh is associated with $R B$.}

The above-mentioned results allow us to hypothesize that a substitution in the $\mathrm{P} 1$ cistron is exclusively responsible for the

CIYVV/C3-S65T (Sato et al. 2004)

\begin{tabular}{|c|c|c|c|c|c|}
\hline & & & & & \\
\hline VPg- P1 GFP HC-Pro & P3 & $\mathrm{Cl}$ & $\mathrm{Nla}$ & $\mathrm{NIb}$ & $\mathrm{CP}$ \\
\hline //C3-S65T & & & & & \\
\hline & & & & & \\
\hline
\end{tabular}

ClYVV/37Brsh-3 (Andrade et al. 2007) derived from pCIYVV/C3-S65T

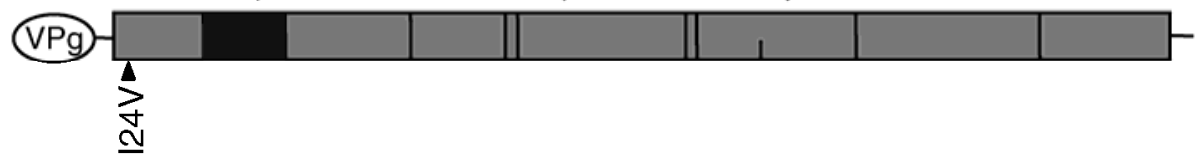

CIYVV/P1I24V constructed from CIYVV/GFP-CP (Yambao et al. 2008)

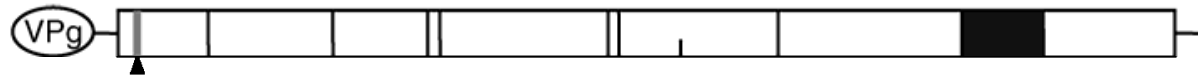

CIYVV/SelF4E (Andrade et al. 2009)

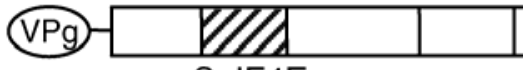

SelF4E

Fig. 1. Clover yellow vein virus plasmid clone (pClYVV) derivatives carrying green fluorescent protein (GFP) and their pathogenicity in a recessive resistance cyv2 pea (PI 378159). Mechanical inoculation with GFP-tagged wild-type ClYVV/C3-S65T rarely caused infection cells. However, its infectious cDNA clone pCIYVV/C3-S65T delivered into cyv2 pea cells by particle bombardment made infection foci in inoculated leaves, eventually resulting in emergence of the resistance-breaking ClYVV/37Brsh, which was able to spread systemically in cyv2 pea. Only one substitution mutation was found in the P1 cistron of the ClYVV/37Brsh isolate 3 genome (ClYVV/37Brsh-3). In this study, the point mutant ClYVV/P1I24V that possessed the single mutation was constructed and was able to break cyv2 resistance. CIYVV/SeIF4E was previously shown to have infectivity in $c y v 2$ pea by complementing the function of the resistant eIF4E with the susceptible eIF4E (SeIF4E) expressed by itself.

Vol. 23, No. 11, 2010 / 1461 


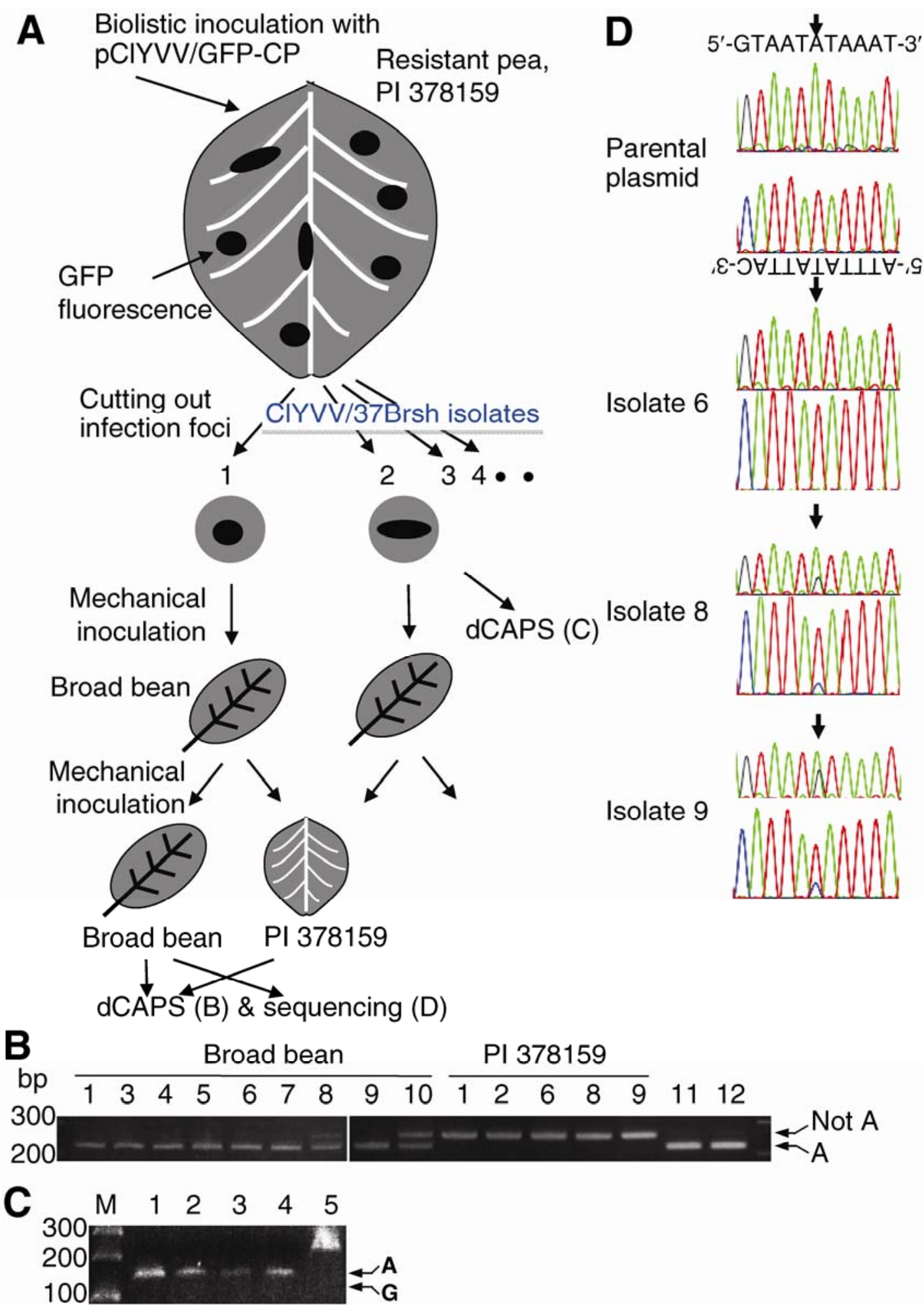

Fig. 2. Association of the single mutation in the $\mathrm{P} 1$ cistron with the resistance-breaking (RB) cyv2 pea. A, Schematic representation for isolating the RB Clover yellow vein virus (ClYVV)/37Brsh from a previous study (Andrade et al. 2007). Biolistic inoculation of cyv2 pea leaves with the infectious cDNA clone pClYVV/GFP-CP made infection foci detected by the green fluorescent protein (GFP) signal. Each of the foci was cut out, and the infected virus was propagated in broad bean. The propagated viruses showed infectivity by mechanical inoculation, not only in broad bean but also in cyv2 pea (PI 378159 ), indicating that these viruses include CIYVV/37Brsh. B, Derived cleaved-amplified polymorphic sequence (dCAPS) marker analysis with PsiI of the propagated virus in broad bean or PI 378159. Partial viral genomic polymerase chain reaction (PCR) fragments including the position corresponding to the mutation I24V were digested with PsiI and were fractionated in agarose gel. The cDNA was not digested when the virus had the mutation (Not A arrowhead). The lane number corresponds to the isolate number of ClYVV/37Brsh (Andrade et al. 2007) except for lanes 11 and 12, both of which were PCR fragments from the wild-type ClYVV/GFP-CP. C, dCAPS marker analysis with AfaI of the propagated virus in biolistically inoculated leaves of resistant pea PI 378159 with pClYVV/C3-S65T plasmid. Four infection foci were analyzed (lanes 1 through 4). Lane 5 is a PCR fragment without digestion by restriction enzyme AfaI. D, PCR fragments of isolates 6, 8, and 9, derived from the viruses propagated in broad bean, and the parental plasmid were directly sequenced. The row data including the mutation position (arrowhead) are partly shown. Isolates 8 and 9 were revealed to be heterogeneous between the viruses with and those without the mutation (A to G). 
RB. In order to investigate the association of the substitution in the $\mathrm{P} 1$ cistron with the RB phenotype, we developed a derived cleaved-amplified polymorphic sequence (dCAPS) marker for detection of the substitution and investigated whether the substitution was shared among ClYVV/37Brsh isolates (Fig. 2). When an isolate does not have the substitution at a position 260 nucleotides from the 5' termini of the CIYVV genome, $255 \mathrm{bp}$ of the PCR cDNA fragment corresponding to the region (nucleotide position 226 to 481 from the $5^{\prime}$ termini of the infected ClYVV genome) can be digested by PsiI, resulting in a 220-bp section of the fragment. As a result, nearly all isolates propagated in broad bean (Fig. 2, lanes 1 and 3 through 10 of broad bean) did not include the substitution. However, isolates propagated in cyv2 pea (Fig. 2, lanes 1, 2, 6, 8, and 9 of PI 378159 ) seemed to be exclusively composed of virus with the substitution, suggesting that $\mathrm{ClYVV/37Brsh}$ is heterogeneous and includes viruses both with and without the substitution and that a proportion of them change depending on host plant. At least five of the ClYVV/37Brsh isolates (isolates 1, 3, 6, 8, and 9) differed between viruses propagated in broad bean and those in cyv2 pea (P1 378159).

The dCAPS analysis in Figure 2 did not provide information about which nucleotide was substituted for adenosine at position 260 from the $5^{\prime}$ termini of the viral genome in each of the ClYVV/37Brsh isolates. A cDNA fragment of viral genomic RNA including the position of the substitution was amplified in RNA extracts from a ClYVV/37Brsh-infected leaf by reverse transcription-polymerase chain reaction (RT-PCR). Direct sequencing of the PCR fragments detected signals corresponding to guanosine as well as adenosine in two out of three isolates propagated in broad bean (Fig. 2D, isolates 8 and 9), suggesting that the substitution (adenosine to guanosine) first found in isolate 3 was shared among most ClYVV/37Brsh iso- lates. The results also confirmed the idea that ClYVV/37Brsh was heterogeneous and composed of those with and without the substitution. We also analyzed the association of the mutation in the $\mathrm{P} 1$ cistron with the cyv2 RB in another cyv2 pea line, W6-15452. Four isolates of the RB viruses possessed the same substitution as that in ClYVV/37Brsh. The results of sequencing and dCAPS analysis of RB viruses were summarized in Supplementary Table S1. We conclude that the A to G nucleotide substitution which resulted in amino-acid substitution isoleucine to valine at amino acid position 24 from the beginning of the P1 cistron, was always associated with cyv2-RB. Because dCAPS analysis failed to detect the substitution in genome of ClYVV/37Brsh isolates in PI 378159 resistant pea leaves biolistically inoculated with $\mathrm{pClYVV/GFP-CP}$ plasmid (Fig. 2C), the virus possessing the substitution seems to be positively selected when breaking the resistance systemically in PI 378159.

\section{Virus genome replication did not produce the substitution errors at the position mediating the $\mathrm{RB}$ preferentially in susceptible plants.}

The fact that the analyzed RB virus ClYVV/37Brsh isolates always possess the same single mutation in the P1 cistron allowed us to investigate the possibility that the $\mathrm{P} 1$ point mutant emerged during propagation of ClYVV even in a susceptible plant without selection pressure. dCAPS analysis of viral genomes in susceptible pea leaves biolistically inoculated with pClYVV/GFP-CP plasmid did not detect the substitution (Fig. $3 \mathrm{~A})$. We then investigated the substitution in progeny viruses propagated in upper leaves, by deep sequencing of each of 4,065 to 4,963 cDNA fragments corresponding to the region of the CIYVV genome including the position of the P1 mutation. A susceptible broad bean was first inoculated with pClYVV/

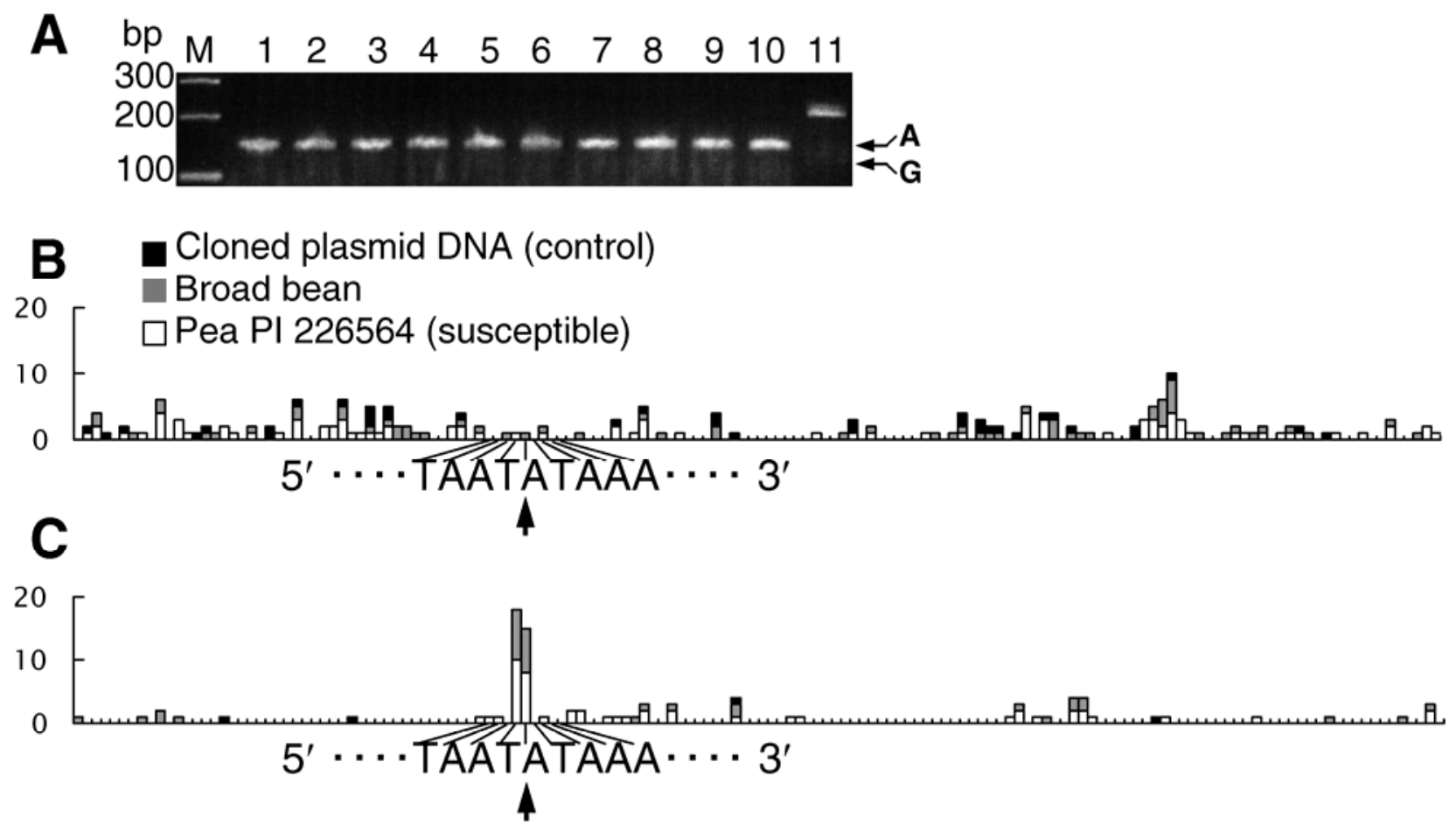

Fig. 3. Accumulation of mutations in Clover yellow vein virus (ClYVV) progeny propagated in susceptible plants without selection pressure. A, Progenies in susceptible pea leaves biolisitically inoculated with pClYVV/C3-S65T infectious plasmid was analyzed by derived cleaved-amplified polymorphic sequence with AfaI (lanes 1 through 10). Lane 11 is a polymerase chain reaction fragment without digestion by the restriction enzyme AfaI. The accumulation of $\mathbf{B}$, substitution and $\mathbf{C}$, deletion mutations in 150-bp viral genomic cDNAs, including the position mediating cyv2-RB (resistance-breaking) (arrowhead), investigated by deep-sequencing analysis. Deep sequencing determined the nucleotide sequences of cDNA fragments derived from the infectious plasmid clone (4,963 fragments), broad bean sample (4,336 fragments), and susceptible pea PI 226564 (4,065 fragments). The number of detected mutations at each position in 150 nucleotides of cDNAs is plotted. 
GFP-CP plasmid and a systemically infected upper leaf was harvested and used for sequencing analysis and inoculum. Then, a susceptible pea, PI 226564, was inoculated and the progeny virus in an upper leaf was analyzed. The substitution involved in the RB was not generated, at least in viral genomes of about 4,000 progenies in broad bean and pea (Fig. 3B). However, the deletion at the position mediating $\mathrm{RB}$ preferentially occurred in progeny viruses in broad bean and pea leaves (Fig. 3C). This deletion was not due to artificial errors generated in deepsequencing processes, as the deletion was not detected in deepsequencing of PCR fragments amplified from a CIYVV infectious plasmid. The progeny viruses possessing the deletion would be lethal because of causing a frame shift in the ORF by the deletion. Thus, the deletion mutation rate (about $0.25 \%$ ) would be replication errors of the CIYVV genome by viral replicase.

\section{Virulence of the point mutant in cyv2 pea.}

In order to examine whether the substitution in the P1 cistron was responsible for the $\mathrm{RB}$, we constructed the infectious plasmid clone of the point mutant (ClYVV/P1I24V) from GFPtagged ClYVV (Fig. 1, ClYVV/GFP-CP). After propagating in broad bean biolistically inoculated with the constructed plasmid, ClYVV/P1I24V was able to systemically infect cyv2 peas by conventional mechanical inoculation (Figs. 4 and 5), indicating that the substitution in the P1 cistron is sufficient for $\mathrm{RB}$. The substitution in $\mathrm{P} 1$ was retained during propagation of $\mathrm{ClYVV/P1I24V} \mathrm{in} \mathrm{broad} \mathrm{bean} \mathrm{and} \mathrm{its} \mathrm{breaking} \mathrm{resistance} \mathrm{in}$ cyv2 pea (Fig. 4C, lanes 2 through 6). However, because we were unable to rule out the possibility that additional mutations occurred during propagation of ClYVV/P1I24V in cyv2 pea and that such mutations contributed to the RB, we investigated the nucleotide sequences of the progeny genome in cyv2 pea. Sequencing the entire region corresponding to the ORF failed to detect any additional mutation (data not shown).

We then compared viral movement of ClYVV/P1I24V with the parental viruses, ClYVV/GFP-CP and ClYVV/37Brsh-3. In a susceptible pea, PI 226564, CIYVV/P1I24V and ClYVV/GFP-CP showed comparable virulence in terms of cell-to-cell movement in an inoculated leaf (Fig. 4A), establishment of systemic infection (Fig. 5C), and symptom severity in an upper noninoculated leaf (not shown). The dCAPS analysis of the ClYVV/P1I24V progeny in PI 226564 (Fig. $4 \mathrm{C}$, lanes 7 and 8 ) ruled out the possibility that the revertant of $\mathrm{ClYVV/P1I24V} \mathrm{was} \mathrm{caused} \mathrm{and} \mathrm{dominantly} \mathrm{propagated} \mathrm{in} \mathrm{a}$ susceptible pea and the revertant represented the comparable virulence with $\mathrm{ClYVV/GFP-CP}$. These results suggest that the point mutation in the $\mathrm{P} 1$ cistron did not produce an obvious defect in the virulence of ClYVV in a susceptible plant. In cyv2 resistant pea PI 378159, ClYVV/P1I24V and ClYVV/ 37Brsh-3 showed comparable virulence (Figs. 4B and 5B, Supplementary Fig. S1), indicating that even if other mutations are present in ClYVV/37Brsh-3, these mutations did not significantly contribute to the virulence of ClYVV/37Brsh-3 in PI 378159. Therefore, taken together, the results described above suggest that the single mutation in the P1 cistron is necessary and sufficient for ClYVV/37Brsh to break cyv2 resistance.

We have another recombinant ClYVV that can break cyv2 resistance by expressing a susceptible type of eIF4E protein (Fig. 1, ClYVV/SeIF4E), whose cDNA was obtained from a susceptible pea (Andrade et al. 2009). In this study, we compared its virulence in $c y v 2$ pea PI 378159 with that of ClYVV/ P1I24V. ClYVV/SeIF4E established infection (Fig. 5A), cell-tocell movement (Fig. 4A and B), and systemic infection similarly in both cyv2 resistant and susceptible peas (Fig. 5B and C). Additionally, ClYVV/SeIF4E propagated in the cyv2 pea was confirmed not to generate progeny with the substitution in the P1 cistron (Fig. 4D), indicating that the completely restored compatibility with cyv2 pea was exclusively due to the expressed SeIF4E protein. In contrast, CIYVV/P1I24V showed slower cell-to-cell movement and establishment of systemic infection in the cyv2 resistant pea than in the susceptible pea. Thus, substitution in the P1 cistron restored compatibility with cyv2 pea, but the restoration was not complete.

\section{DISCUSSION}

This study revealed, for the first time, that a potyviral P1 protein is involved in the virus overcoming eIF4E-mediated recessive resistance. Two recessive resistance genes, $c y v 1$ and cyv2, against ClYVV are found in pea. In both cases, conventional mechanical inoculation rarely caused infection, even in an inoculated leaf. However, we recently found that the durability of these resistances decreased after biolistic inoculation of the infectious plasmid clone, which constitutively transcribes a capped CIYVV RNA genome at its 5' terminus instead of VPg (Andrade et al. 2007). Especially, in a cyv2 pea, in which mutations in eIF4E confer resistance, the progeny virus moves from cell to cell in the inoculated leaf and then infects systemically in most inoculated cyv2 pea PI 378159, although the viral spread as monitored by GFP was slower than that in a susceptible pea. Because cyv2 pea could be infected by mechanical inoculation with the progeny obtained at a systemic leaf in cyv2 pea but not with wild-type CIYVV, the progeny should have mutations that enable the progeny to overcome the cyv2 resistance. We naturally assumed that one or more responsible mutations were located in $\mathrm{VPg}$, because mutations in VPg have exclusively been associated with the breaking of eIF4E-mediated resistance by several other potyviruses (Ayme et al. 2007; Hebrard et al. 2006; Masuta et al. 1999; Moury et al. 2004; Sato et al. 2003), except for mutations in CI of LMV associated with breaking resistance $\mathrm{mol}^{l}$ and $\mathrm{mol}^{2}$ in lettuce (Abdul-Razzak et al. 2009). There might be other exceptional cases in which mutations in P3 of PSbMV are associated with breaking recessive resistance, for which the resistance gene in pea remains to be identified (Hjulsager et al. 2006; Johansen et al. 2001). However, in our case, a single mutation in the P1 cistron of ClYVV/37Brsh seems necessary and sufficient to break the resistance.

As the mutation was located in the N-proximal part of $\mathrm{P} 1$, this study would argue vital functions for the N-proximal part. Consistently, an accessory function of P1 stimulated viral multiplication, as indicated by the 85 to 90 or 97 to $98 \%$ reduction of virus accumulation in Nicotiana tabacum protoplasts following removal of the N-proximal part or the entire P1 coding region from Tobacco etch virus (TEV) (Verchot and Carrington 1995a and b). The N-proximal part of the P1 protein has also been shown to interact with the cytochrome b6/f complex Rieske Fe/S proteins of host and nonhost plants (Shi et al. 2007). Mutations in this part of the P1 gene change the virulence of LMV to some lettuce cultivars (Krause-Sakate et al. 2005). These previous studies implicate P1 protein, especially its $\mathrm{N}$-proximal part, in viral multiplication, virulence, and interaction with host plants. Further studies aimed at understanding the mechanism of P1 involvement in breaking the eIF4E-mediated cyv2 resistance would yield insight into the functions of $\mathrm{P} 1$.

How is $\mathrm{P} 1$ involved in breaking the $c y v 2$ resistance? Recent independent studies revealed that $c y v 2$ was the same allele encoding the eIF4E gene with $s b m l$ and $w l m$ resistant to potyviruses PSbMV and BYMV, respectively (Andrade et al. 2009). Mutant viruses of these that can overcome the resistance rendered by the same eIF4E allele were isolated, and mutations in their VPg cistrons were reported to be responsible for the RB, 

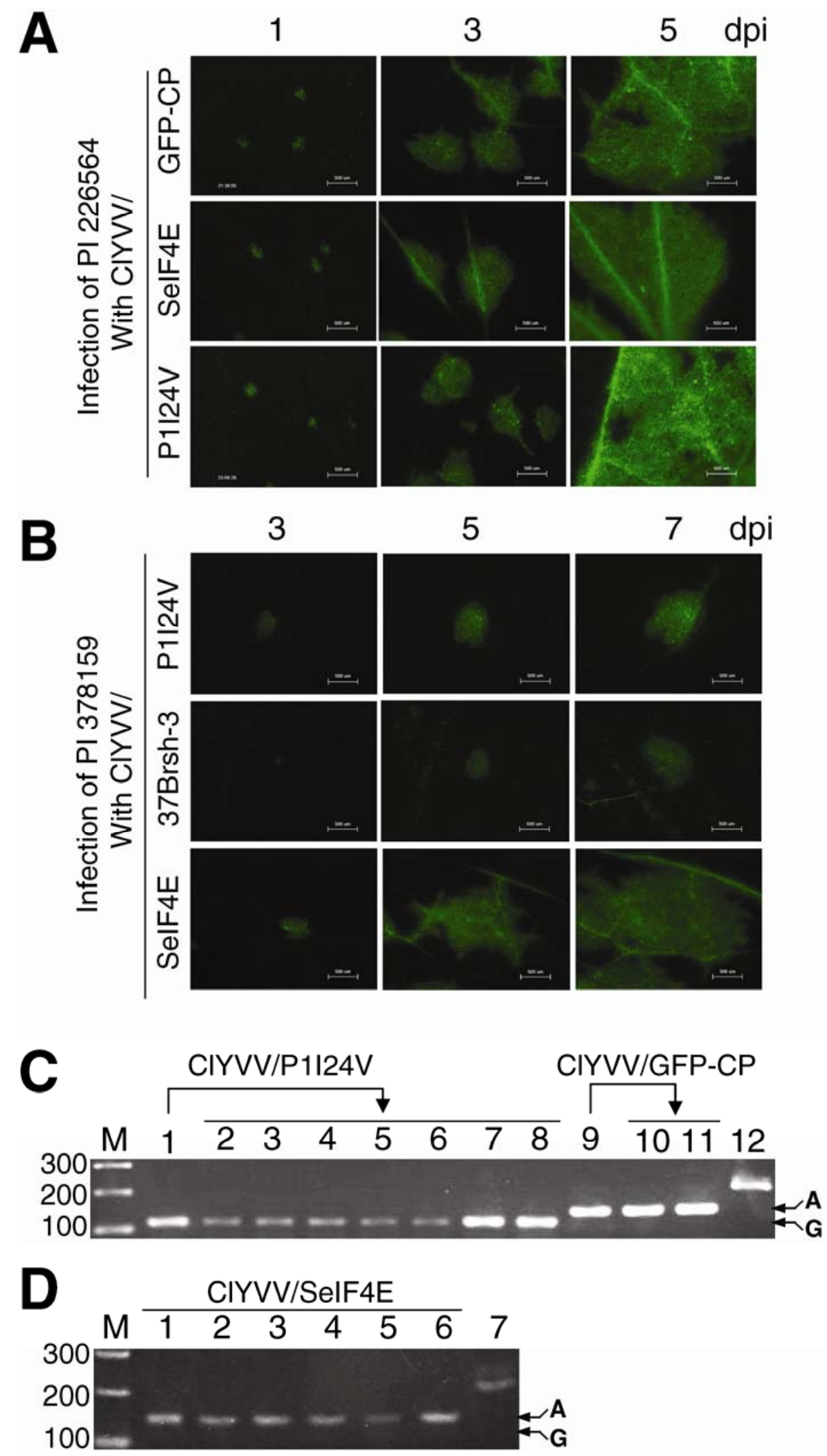

Fig. 4. Virulence of Clover yellow vein virus (ClYVV)/GFP-CP, ClYVV/P1I24V, ClYVV/37Brsh-3, and ClYVV/SeIF4E in a cyv2 pea (PI 378159). A, Viral spread in the inoculated leaf of a susceptible pea was monitored as green fluorescent protein (GFP) fluorescence expressed by the viruses at 1,3 , and 5 days postinoculation (dpi). Bars $=500 \mu \mathrm{m}$. B, Viral spread in the inoculated leaf of a resistant pea was monitored at 3, 5, and $7 \mathrm{dpi}$. Bars $=500 \mu \mathrm{m}$. $\mathbf{C}$, Derived cleaved-amplified polymorphic sequence (dCAPS) marker analysis to investigate whether the progeny viruses possess the mutation in the P1 cistron. Shorter (arrow with G) and longer (arrow with A) fragments were produced by AfaI digestion of polymerase chain reaction (PCR) fragments with and without the mutation in the P1 cistron, respectively. The viruses propagated in broad bean inoculated with the infectious clones (lanes 1 and 9) were inoculated into a resistant pea, PI 378159 (lanes 2 through 6), and a susceptible pea (lanes 7, 8, 10, and 11). Lane 12 is the PCR fragment of lane 11 without AfaI digestion. D, dCAPS marker analysis to confirm that the systemically infected CIYVV/SeIF4E progenies did not have the mutation in the P1 cistron (lanes 1 through 6). Lane 7 is the PCR fragment of lane 6 without AfaI digestion. 

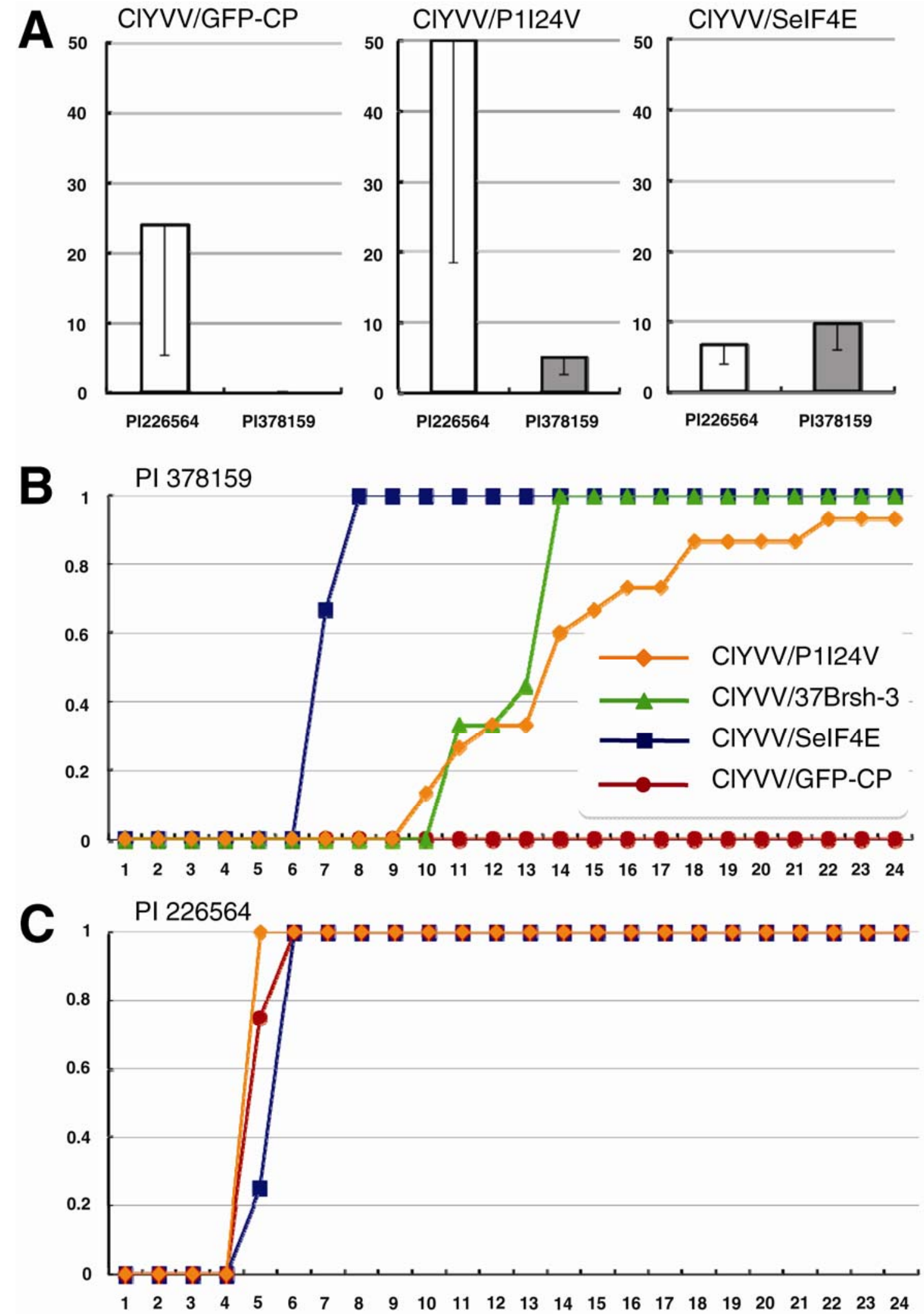

Fig. 5. Partial restoration of compatibility of Clover yellow vein virus (CIYVV) with the cyv2 pea by point mutation in the P1 cistron. A, Comparison of the number of infection foci in inoculated leaves between susceptible and resistant pea lines (PI 226564 and PI 378159). Leaves of both lines were inoculated using the same inoculum. Infection foci were detected by green fluorescent protein (GFP) fluorescence. The numbers are the average per one leaf. B, Comparison of systemic spread of inoculated viruses, wild-type ClYVV/GFP-CP (red circle, $n=12$ ), the point mutant ClYVV/P1I24V (orange diamond, $n=15$ ), the resistance-breaking (RB) ClYVV/37Brsh-3 (green triangle, $n=9$ ), ClYVV expressing the susceptible eIF4E, and ClYVV/SeIF4E (blue square, $n=6$ ) in the resistant pea line PI 378159. Systemic infection of the inoculated viruses was monitored by observation of symptom expression and confirmed by detecting GFP fluorescence until 24 days postinoculation (dpi). The proportion of systemically infected plants is plotted in a graph. C, Comparison of systemic spread of inoculated viruses in the susceptible pea line PI 226564. The analysis was done as described in B. Tested viruses are ClYVV/GFP-CP (red circle, $n=4)$, the point mutant ClYVV/P1I24V (orange diamond, $n=2$ ), ClYVV expressing the susceptible eIF4E, and ClYVV/SeIF4E (blue square, $n=4$ ). 
as were cases with other potyviruses in eIF4E-mediated resistant plants. Thus, it is likely that VPg is also a key factor in breaking the $c y v 2$ resistance by ClYVV/37Brsh.

Contemporary understanding of the VPg-eIF4E interaction in eIF4E-mediated recessive resistance against potyvirus can be summarized with recent works studying the TEV and Potato virus $Y$ (PVY) and Capsicum pathosystem. i) Binding between VPg and eIF4E was disrupted by natural mutations in eIF4E alleles, and the interruption of the binding was correlated with potyvirus resistance (Charron et al. 2008; Kang et al. 2005). ii) The amino-acid substitution G107R among mutations in eIF4E was responsible for the interruption of VPg binding (Yeam et al. 2007). iii) Viral adaptation to eIF4E-mediated resistance resulted from a restored interaction of VPg with eIF4E alleles by mutations in VPg (Charron et al. 2008). Interestingly, the eIF4E allele in the cyv2 pea shares the G107R substitution. These facts suggest that the resistance resulted from less affinity between VPg and the eIF4E allele in pea, and the binding is restored by mutations in $\mathrm{VPg}$ of the RB isolates of PSbMV and BYMV and in P1 of ClYVV/37Brsh.

If so, can $\mathrm{P} 1$ protein affect binding between VPg and eIF4E? Previously, binding of P1 to VPg as well as to HC-Pro, P3, CI, NIa-pro, NIb, and CP were shown, using in vitro analyses of proteins encoded by Potato virus A (Merits et al. 1999). Consistently, we have reported the interaction between VPg and HC-Pro of ClYVV (Yambao et al. 2003). The interaction between HC-Pro and P1 of ClYVV was also confirmed (Supplementary Fig. 2). However, as both lettuce eIF4E and HC-Pro of LMV were reported to interact with LMV VPg at its central domain and compete for the binding site (Roudet-Tavert et al. 2007), we cannot simply assume the complex including P1, HC-Pro, VPg, and eIF4E. Perhaps, an accessory function of P1 to form a complex including the binding of VPg to eIF4E may explain why the single mutation in $\mathrm{P} 1$ does not fully restore the compatibility with cyv2 pea; the point mutant ClYVV/P1I24V showed a smaller number of infection foci, slower cell-to-cell movement in inoculated leaves, and slower development of systemic infection than did those with ClYVV/SeIF4E in cyv2 pea. Although how P1 is involved in $\mathrm{RB}$ remains to be investigated, $\mathrm{P} 1$ autoproteolytic activity, interaction with HC-Pro, and distribution in tobacco cells were not affected by the substitution in P1 (Supplementary Fig. S3)

The above discussion simply raises the question of why CIYVV breaks the cyv2 resistance by causing a mutation in $\mathrm{P} 1$ but not in VPg, like those in the RB viruses of BYMV and PSbMV. Moreover, all the RB virus isolates analyzed had the exact same substitution (A to $G$ ) in the P1 cistron. Although the mechanism is not clear, it is interesting to note that de novo deletion but not the substitution at the position mediating RB preferentially occurred in susceptible plants without positive selection pressure (Fig. 3C). The arms race between Capsicum plants and potyviruses PVY and TEV based on eIF4E-mediated recessive resistance and $\mathrm{RB}$ with $\mathrm{VPg}$ mutations has recently been implicated (Charron et al. 2008). The RB virus with P1 mutation may be another branch in the arms race.

\section{MATERIALS AND METHODS}

\section{Plants and viruses.}

Resistant pea lines carrying cyv2 against ClYVV, PI 378159, and W6-15452 (Andrade et al. 2009; Provvidenti 1987), and susceptible line PI 226564 were provided by C. Coyne, Western Regional Plant Introduction Station, Washington State University, Pullman, WA, U.S.A. Recombinant ClYVV derivatives used in this study are listed in Figure 1. The infectious clone of ClYVV tagged with GFP (pClYVV/C3-S65T) (Sato et al. 2003) was derived from infectious clone pClYVV, which was con- structed from ClYVV strain No. 30 (Takahashi et al. 1997). CIYVV expressing a susceptible type of eIF4E (SeIF4E) and GFP (ClYVV/SeIF4E-GFP) (Andrade et al. 2009) was also previously constructed from $\mathrm{pClYVV/GFP-CP}$ in which GFP was inserted between viral Nib and CP (Wang et al. 2003) by inserting SeIF4E between the P1 and HC-Pro cistrons. The RB ClYVV in cyv2 pea PI 378159 (ClYVV/37Brsh) derived from $\mathrm{pClYVV/C3-S65T} \mathrm{was} \mathrm{obtained} \mathrm{in} \mathrm{our} \mathrm{previous} \mathrm{study} \mathrm{(Andrade}$ et al. 2007) and is outlined in Figure 2A. All plasmids were particle-bombarded into broad bean (Vicia faba) (Gal-On et al. 1997); then, the virus particles were recovered from systemically infected leaves and were used as inoculum.

\section{Construction of infectious viral cDNA clones.}

The ClYVV infectious clone with the point mutation (pClYVV/P1I24V), adenosine to guanine at position 260 on the ClYVV genome, corresponding to an amino-acid substitution at position 24 (isoleucine to valine) on the $\mathrm{P} 1$ protein, was made from pClYVV-GFP-CP by site-directed mutagenesis, as described by Yambao and associates (2008).

\section{Sequencing and dCAPS marker analyses of viral genomic cDNAs.}

Total RNA was isolated from infected pea and broad bean leaves using Trizol reagent (Invitrogen Carlsbad, CA, U.S.A.). The cDNA was synthesized using reverse transcriptase, cloned AMV (Invitrogen), or ReverTra Ace (TOYOBO, Osaka, Japan) with random 9-mer, according to the manufacturer's manual. PCR was carried out using thermostable DNA polymerases GO-Taq DNA polymerase (Promega, Madison, WI, U.S.A.) for dCAPS marker analysis and Ex-Taq (TaKaRa, Ohtsu, Japan) for direct sequencing. In order to detect PCR fragments amplified with sense and antisense primers, 5'-CTTAAACAAGGA ATCTAGTGTTTCTGAGAGTATT-3' (nucleotide position 226 to 259 from $5^{\prime}$ termini of ClYVV genome) and 5'-CTTTTCC TCTTCCACTAAACG-3' (nucleotide position 481 to 46) were digested with $P$ siI and were fractionated in agarose gel electrophoresis for dCAPS marker analysis (Fig. 2). PCR fragments amplified with primer pair 5'-AACAAAGCAAAGTAAGCC AACAGTTTTCTG-3' (nucleotide position 81 to 110 ) and $5^{\prime}$ TTGTTTTAGGAATAATACTACTAATATGTA-3' (nucleotide position 290 to 261) were digested with $A f a I$ and were fractionated in agarose gel electrophoresis for dCAPS marker analysis (Fig. 3). Direct sequencing of the entire region of the ORF of ClYVV/P1I24V progeny in an upper leaf of cyv2 pea PI 378159 was performed as follows. Four cDNA fragments overlapping the entire ORF were amplified by RT-PCR with four primer pairs: i) 5'-AACAAAGCAAAGTAAGCCAACAG TTTTCTG-3' and 5'-TACCTAGTAATTTCAAGTAAGCTCG3', ii) 5'-ACCATACAAGCTGAGGGACTCAAATGTTGT-3' and 5'-AGTTCAGTCGAAGTCTCAGAAC-3', iii) 5'-ACGTG TACATCAGATCTCAATGTAAT-3' and 5'-TTTTGATGTGA GATCTCACTTGACTC-3', and iv) 5'-AGTCTCCATCTTGA GATACCC-3' and 5'-CCCAGATCTTACATATTATACTTAAA GTGAAATG-3'. These PCR fragments were directly sequenced with primers used for their amplification. The rest of the nucleotide sequences of the four PCR fragments to be determined were then directly sequenced with appropriate primers.

\section{Virus infection and spread monitored in pea by observation of symptom expression and detection of GFP fluorescence after inoculation.}

In mechanically inoculated leaves, infection foci were monitored by detection of GFP fluorescence with a fluorescence microscope system (VB-7010; Keycence, Osaka, Japan) with a band-pass GFP filter (FF01-520/35-25; Semrock, Rochester, NY, U.S.A.). Systemic infection was monitored by observation 
of symptom expression in upper leaves and was confirmed by detection of GFP fluorescence, as in inoculated leaves.

\section{Deep sequencing analysis.}

A susceptible broad bean was first inoculated with pClYVV/GFP-CP plasmid and a systemically infected upper leaf was harvested and used for sequencing analysis and inoculum. Then, susceptible pea PI 226564 was mechanically inoculated with the broad bean inoculum and the progeny virus in an upper leaf was analyzed. Total RNA was extracted from upper leaves of ClYVV/GFP-CP-infected broad bean and susceptible pea PI 226564 using Trizol reagent 12 days after inoculation, and their cDNA was synthesized as described above. The 150-bp viral genomic cDNA sequence including the position that mediated the cyv2-RB of ClYVV/GFP-CP progenies was amplified by PCR in the synthesized cDNAs, using a high fidelity DNA polymerase Phusion (Finnzymes, Espoo, Finland). As a control, the PCR product was also amplified from the ClYVV/GFP-CP infectious plasmid clone. The PCR reaction mixture $(50 \mu \mathrm{l})$ included template cDNA or plasmid DNA, $10 \mu \mathrm{l}$ of $5 \times$ HF buffer (Finnzymes), $1 \mu \mathrm{l}$ of $10 \mathrm{mM}$ dNTPs, 1 unit Phusion DNA polymerase, and $2 \mu \mathrm{l}$ of $20 \mu \mathrm{M}$ sense and antisense primers, 5'-CCAAGCAATGGCACAAAT CATGATTGG- ${ }^{\prime}$ ' and 5'-CCATTGCAAGCTAGAGTTATCGC TTTG-3' for the broad bean sample, 5'-CACAGCAATGGCA CAAATCATGATTGG-3' and 5'-CACTTGCAAGCTAGAGT TATCGCTTTG-3' for the pea sample, and 5'-CGAAGCAATG GCACAAATCATGATTGG-3' and 5'-CGATTGCAAGCTAG AGTTATCGCTTTG-3' for the control plasmid sample, at $98^{\circ} \mathrm{C}$ for $30 \mathrm{~s}$, and 30 cycles of $98^{\circ} \mathrm{C}$ for $30 \mathrm{~s}, 60^{\circ} \mathrm{C}$ for $30 \mathrm{~s}$, and $72^{\circ} \mathrm{C}$ for $30 \mathrm{~s}$, and finally, $72^{\circ} \mathrm{C}$ for $7 \mathrm{~min}$. Then, these PCR fragments were fractionated in agarose gel electrophoresis and were purified. In order to reduce the sequencing cost, equal amounts of the purified PCR fragments were mixed and applied as one sample for pyrosequencing, using a Genome Sequencer FLX system (Roche, Basel, Switzerland). The determined nucleotide sequences of each PCR fragment were sorted by their terminal short tag sequences; the broad bean sample, the pea sample, and the plasmid sample have CCA, CAC, and CGA tag sequences, respectively. These determined nucleotide sequences were aligned, and substitution and deletion mutations were detected using eBioX software, always excepting deletion mutations in repeat sequence of the same nucleotide that were actually detected in the sequences derived from the control plasmid clone, because pyrosequencing tends to produce errors in determining the number of the repeat sequence of the same nucleotide.

\section{Immunoprecipitation.}

P1/HC-Pro (HA at the C-terminal of HC-Pro)-associated proteins in a reaction solution of in vitro translations of HAP1/HC-Pro containing ${ }^{35} S$-methionine (TNT, T7 Quick for PCR DNA; Promega), the solution was used for immunoprecipitation with anti-HA monoclonal antibody-agarose (Sigma-Aldrich, St. Louis). After fractionation of the precipitated proteins by sodium dodecyl sulfate-polyacrylamide gel electrophoresis, the radio isotope signal was detected with a Bio-image Analyzer (BAS 1000; Fuji Photo Films, Tokyo, Japan).

\section{In situ proximity ligation assay (PLA).}

At $16 \mathrm{~h}$ after transfection of BY2 protoplasts, treated cells were fixed on slides and reacted with primary antibodies, basically according to the protocol in Part B on The Arabidopsis Information Resources website, with slight modifications. Slides were precoated with $0.005 \%$ poly-L-lysine (Sigma-Aldrich). Primary antibodies were 60 -fold diluted with blocking solution ( $2 \%$ bovine serum albumin). The samples were reacted with the PLA probe (secondary antibody conjugated with oligonucleotides), and after hybridization between PLA probes, ligations, amplifications, and detection with fluorescently labeled oligonucleotides (detection kit 613 [Ex/Em: 598/613]; Olink Bioscience, Uppsala, Sweden) were carried out according to the manufacturer's protocol. The expression and distribution of target proteins are detected by a 'single recognition PLA.' The in situ-specific interaction between two proteins, P1 and HC-Pro, was detected by a 'double recognition PLA.' Photomicrographs were taken using a Leica DMI6000 B microscope (Leica Microsystems, Bannockburn, IL, U.S.A.). Image colors were then reassigned using AF6000 ver. 1.5 software as follows: a PLA signal, red; Hoechst 33342, blue.

\section{ACKNOWLEDGMENTS}

This work was partly supported by Grant-in-Aid for Scientific Research and Young Scientists (17780032, 18108001, 20688002) to K. S. Nakahara and I. Uyeda from the Ministry of Education, Science, Sports and Culture, Japan.

\section{LITERATURE CITED}

Abdul-Razzak, A., Guiraud, T., Peypelut, M., Walter, J., Houvenaghel, M. C., Candresse, T., Le Gall, O., and German-Retana, S. 2009. Involvement of the cylindrical inclusion (CI) protein in the overcoming of an eIF4E-mediated resistance against Lettuce mosaic potyvirus. Mol. Plant Pathol. 10:109-113

Adams, M. J., Antoniw, J. F., and Fauquet, C. M. 2005. Molecular criteria for genus and species discrimination within the family Potyviridae. Arch. Virol. 150:459-479.

Albar, L., Bangratz-Reyser, M., Hebrard, E., Ndjiondjop, M. N., Jones, M., and Ghesquiere, A. 2006. Mutations in the eIF(iso)4G translation initiation factor confer high resistance of rice to Rice yellow mottle virus. Plant J. 47:417-426.

Anandalakshmi, R., Pruss, G. J., Ge, X., Marathe, R., Mallory, A. C., Smith, T. H., and Vance, V. B. 1998. A viral suppressor of gene silencing in plants. Proc. Natl. Acad. Sci. U.S.A. 95:13079-13084.

Andrade, M., Sato, M., and Uyeda, I. 2007. Two resistance modes to Clover yellow vein virus in pea characterized by a green fluorescent protein-tagged virus. Phytopathology 97:544-550.

Andrade, M., Abe, Y., Nakahara, K. S., and Uyeda, I. 2009. The cyv-2 resistance to Clover yellow vein virus in pea is controlled by the eukaryotic initiation factor 4E. J. Gen. Plant Pathol. 75:241-249.

Arbatova, J., Lehto, K., Pehu, E., and Pehu, T. 1998. Localization of the $\mathrm{P} 1$ protein of potato $\mathrm{Y}$ potyvirus in association with cytoplasmic inclusion bodies and in the cytoplasm of infected cells. J. Gen. Virol. 79:2319-2323.

Ayme, V., Petit-Pierre, J., Souche, S., Palloix, A., and Moury, B. 2007. Molecular dissection of the potato virus Y VPg virulence factor reveals complex adaptations to the $p v r 2$ resistance allelic series in pepper. $\mathrm{J}$. Gen. Virol. 88:1594-1601.

Beauchemin, C., Boutet, N., and Laliberte, J. F. 2007. Visualization of the interaction between the precursors of $\mathrm{VPg}$, the viral protein linked to the genome of Turnip mosaic virus, and the translation eukaryotic initiation factor iso 4E in Planta. J. Virol. 81:775-782.

Brantley, J. D., and Hunt, A. G. 1993. The N-terminal protein of the polyprotein encoded by the potyvirus tobacco vein mottling virus is an RNA-binding protein. J. Gen. Virol. 74:1157-1162.

Brigneti, G., Voinnet, O., Li, W. X., Ji, L. H., Ding, S. W., and Baulcombe, D. C. 1998. Viral pathogenicity determinants are suppressors of transgene silencing in Nicotiana benthamiana. EMBO (Eur. Mol. Biol. Organ.) J. 17:6739-6746.

Bruun-Rasmussen, M., Moller, I. S., Tulinius, G., Hansen, J. K. R., Lund, O. S., and Johansen, I. E. 2007. The same allele of translation initiation factor 4E mediates resistance against two Potyvirus spp. in Pisum sativum. Mol. Plant Microbe Interact. 20:1075-1082.

Charron, C., Nicolai, M., Gallois, J. L., Robaglia, C., Moury, B., Palloix, A., and Caranta, C. 2008. Natural variation and functional analyses provide evidence for co-evolution between plant eIF4E and potyviral VPg. Plant J. 54:56-68.

Diaz-Pendon, J. A., Truniger, V., Nieto, C., Garcia-Mas, J., Bendahmane, A., and Aranda, M. A. 2004. Advances in understanding recessive resistance to plant viruses. Mol. Plant Pathol. 5:223-233.

Gal-On, A., Meiri, E., Elman, C., Gray, D. J., and Gaba, V. 1997. Simple hand-held devices for the efficient infection of plants with viral-encoding 
constructs by particle bombardment. J. Virol. Methods 64:103-110.

Gao, Z., Eyers, S., Thomas, C., Ellis, N., and Maule, A. 2004a. Identification of markers tightly linked to $\mathrm{sbm}$ recessive genes for resistance to Pea seed-borne mosaic virus. Theor. Appl. Genet. 109:488-494.

Gao, Z., Johansen, E., Eyers, S., Thomas, C. L., Noel Ellis, T. H., and Maule, A. J. 2004b. The potyvirus recessive resistance gene, sbm1, identifies a novel role for translation initiation factor eIF4E in cell-tocell trafficking. Plant J. 40:376-385.

Hebrard, E., Pinel-Galzi, A., Bersoult, A., Sire, C., and Fargette, D. 2006. Emergence of a resistance-breaking isolate of Rice yellow mottle virus during serial inoculations is due to a single substitution in the genomelinked viral protein VPg. J. Gen. Virol. 87:1369-1373.

Hjulsager, C. K., Lund, O. S., and Johansen, I. E. 2002. A new pathotype of Pea seedborne mosaic virus explained by properties of the P3-6k1and viral genome-linked protein ( $\mathrm{VPg}$ )-coding regions. Mol. Plant Microbe Interact. 15:169-171.

Hjulsager, C. K., Olsen, B. S., Jensen, D. M., Cordea, M. I., Krath, B. N., Johansen, I. E., and Lund, O. S. 2006. Multiple determinants in the coding region of Pea seed-borne mosaic virus $\mathrm{P} 3$ are involved in virulence against $s b m-2$ resistance. Virology 355:52-61.

Hou, H., and Qiu, W. 2003. A novel co-delivery system consisting of a Tomato bushy stunt virus and a defective interfering RNA for studying gene silencing. J. Virol. Methods 111:37-42.

Johansen, I. E., Lund, O. S., Hjulsager, C. K., and Laursen, J. 2001. Recessive resistance in Pisum sativum and potyvirus pathotype resolved in a gene-for-cistron correspondence between host and virus. J. Virol. 75:6609-6614.

Kang, B. C., Yeam, I., Frantz, J. D., Murphy, J. F., and Jahn, M. M. 2005. The pvrl locus in Capsicum encodes a translation initiation factor eIF4E that interacts with Tobacco etch virus VPg. Plant J. 42:392-405.

Kasschau, K. D., and Carrington, J. C. 1998. A counterdefensive strategy of plant viruses: Suppression of posttranscriptional gene silencing. Cell 95:461-470.

Krause-Sakate, R., Redondo, E., Richard-Forget, F., Jadao, A. S., Houvenaghel, M. C., German-Retana, S., Pavan, M. A., Candresse, T., Zerbini, F. M., and Le Gall, O. 2005. Molecular mapping of the viral determinants of systemic wilting induced by a Lettuce mosaic virus (LMV) isolate in some lettuce cultivars. Virus Res. 109:175-180.

Kushner, D. B., Lindenbach, B. D., Grdzelishvili, V. Z., Noueiry, A. O., Paul, S. M., and Ahlquist, P. 2003. Systematic, genome-wide identification of host genes affecting replication of a positive-strand RNA virus. Proc. Natl. Acad. Sci. U.S.A. 100:15764-15769.

Leonard, S., Plante, D., Wittmann, S., Daigneault, N., Fortin, M. G., and Laliberte, J. F. 2000. Complex formation between potyvirus VPg and translation eukaryotic initiation factor $4 \mathrm{E}$ correlates with virus infectivity. J. Virol. 74:7730-7737.

Masuta, C., Nishimura, M., Morishita, H., and Hataya, T. 1999. A single amino acid change in viral genome-associated protein of Potato virus $\mathrm{Y}$ correlates with resistance breaking in 'Virgin A Mutant' tobacco. Phytopathology 89:118-123.

Merits, A., Guo, D., Jarvekulg, L., and Saarma, M. 1999. Biochemical and genetic evidence for interactions between potato A potyvirus-encoded proteins $\mathrm{P} 1$ and $\mathrm{P} 3$ and proteins of the putative replication complex. Virology 263:15-22.

Moreno, M., Bernal, J. J., Jimenez, I., and Rodriguez-Cerezo, E. 1998. Resistance in plants transformed with the P1 or P3 gene of tobacco vein mottling potyvirus. J. Gen. Virol. 79:2819-2827.

Moreno, M., Brandwagt, B. F., Shaw, J. G., and Rodriguez-Cerezo, E. 1999. Infectious virus in transgenic plants inoculated with a nonviable, P1-proteinase defective mutant of a potyvirus. Virology 257:322-329.

Moury, B., Morel, C., Johansen, E., Guilbaud, L., Souche, S., Ayme, V., Caranta, C., Palloix, A., and Jacquemond, M. 2004. Mutations in Potato virus $Y$ genome-linked protein determine virulence toward recessive resistances in Capsicum annuum and Lycopersicon hirsutum. Mol. Plant Microbe Interact. 17:322-329.

Nagy, P. D. 2008. Yeast as a model host to explore plant virus-host interactions. Annu. Rev. Phytopathol. 46:217-242.

Provvidenti, R. 1987. Inheritance of resistance to clover yellow vein virus in Pisum-sativum. J. Hered. 78:126-128.

Provvidenti, R., Hampton, R. O., and Muehlbauer, F. J. 1991. G-1000, Marx's pea breeding line for multiviral resistance. Pisum Genet. 23:50-52.

Pruss, G., Ge, X., Shi, X. M., Carrington, J. C., and Bowman Vance, V. 1997. Plant viral synergism: The potyviral genome encodes a broadrange pathogenicity enhancer that transactivates replication of heterologous viruses. Plant Cell 9:859-868.
Ritzenthaler, C. 2005. Resistance to plant viruses: Old issue, news answers? Curr. Opin. Biotech. 16:118-122.

Robaglia, C., and Caranta, C. 2006. Translation initiation factors: A weak link in plant RNA virus infection. Trends Plant Sci. 11:40-45.

Rodriguez-Cerezo, E., and Shaw, J. G. 1991. Two newly detected nonstructural viral proteins in potyvirus-infected cells. Virology 185:572579.

Roudet-Tavert, G., Michon, T., Walter, J., Delaunay, T., Redondo, E., and Le Gall, O. 2007. Central domain of a potyvirus VPg is involved in the interaction with the host translation initiation factor eIF4E and the viral protein Hc-Pro. J. Gen. Virol. 88:1029-1033.

Sato, M., Masuta, C., and Uyeda, I. 2003. Natural resistance to Clover yellow vein virus in beans controlled by a single recessive locus. Mol. Plant Microbe Interact. 16:994-1002.

Shi, Y., Chen, J., Hong, X., Chen, J., and Adams, M. J. 2007. A potyvirus $\mathrm{P} 1$ protein interacts with the Rieske Fe/S protein of its host. Mol. Plant Pathol. 8:785-790.

Soumounou, Y., and Laliberte, J. F. 1994. Nucleic acid-binding properties of the P1 protein of turnip mosaic potyvirus produced in Escherichia coli. J. Gen. Virol. 75:2567-2573.

Takahashi, Y., Takahashi, T., and Uyeda, I. 1997. A cDNA clone to clover yellow vein potyvirus genome is highly infectious. Virus Genes 14:235243.

Valli, A., Lopez-Moya, J. J., and Garcia, J. A. 2007. Recombination and gene duplication in the evolutionary diversification of $\mathrm{P} 1$ proteins in the family Potyviridae. J. Gen. Virol. 88:1016-1028.

Verchot, J., and Carrington, J. C. 1995a. Evidence that the potyvirus P1 proteinase functions in trans as an accessory factor for genome amplification. J. Virol. 69:3668-3674.

Verchot, J., and Carrington, J. C. 1995b. Debilitation of plant potyvirus infectivity by $\mathrm{P} 1$ proteinase-inactivating mutations and restoration by second-site modifications. J. Virol. 69:1582-1590.

Verchot, J., Koonin, E. V., and Carrington, J. C. 1991. The 35-kDa protein from the $\mathrm{N}$-terminus of the potyviral polyprotein functions as a third virus-encoded proteinase. Virology 185:527-535.

Verchot, J., Herndon, K. L., and Carrington, J. C. 1992. Mutational analysis of the tobacco etch potyviral $35-\mathrm{kDa}$ proteinase: Identification of essential residues and requirements for autoproteolysis. Virology 190:298-306.

Wang, Z. D., Ueda, S., Uyeda, I., Yagihashi, H., Sekiguchi, H., Tacahashi, Y., Sato, M., Ohya, K., Sugimoto, C., and Matsumura, T. 2003. Positional effect of gene insertion on genetic stability of a clover yellow vein virus-based expression vector. J. Gen. Plant Pathol. 69:327-334.

Wittmann, S., Chatel, H., Fortin, M. G., and Laliberte, J. F. 1997. Interaction of the viral protein genome linked of turnip mosaic potyvirus with the translational eukaryotic initiation factor (iso) $4 \mathrm{E}$ of Arabidopsis thaliana using the yeast two-hybrid system. Virology 234:84-92.

Yambao, M. L., Masuta, C., Nakahara, K., and Uyeda, I. 2003. The central and C-terminal domains of VPg of Clover yellow vein virus are important for VPg-HCPro and VPg-VPg interactions. J. Gen. Virol. 84:28612869 .

Yambao, M. L. M., Yagihashi, H., Sekiguchi, H., Sekiguchi, T., Sasaki, T., Sato, M., Atsumi, G., Tacahashi, Y., Nakahara, K. S., and Uyeda, I. 2008. Point mutations in helper component protease of clover yellow vein virus are associated with the attenuation of RNA-silencing suppression activity and symptom expression in broad bean. Arch. Virol. 153:105-115.

Yang, L. J., Hidaka, M., Masaki, H., and Uozumi, T. 1998. Detection of potato virus Y P1 protein in infected cells and analysis of its cleavage site. Biosci. Biotechnol. Biochem. 62:380-382.

Yeam, I., Cavatorta, J. R., Ripoll, D. R., Kang, B. C., and Jahn, M. M. 2007. Functional dissection of naturally occurring amino acid substitutions in eIF4E that confers recessive potyvirus resistance in plants. The Plant cell 19:2913-2928.

Yoshii, M., Nishikiori, M., Tomita, K., Yoshioka, N., Kozuka, R., Naito, S., and Ishikawa, M. 2004. The Arabidopsis cucumovirus multiplication 1 and 2 loci encode translation initiation factors 4E and 4G. J. Virol. 78:6102-6111.

\section{AUTHOR-RECOMMENDED INTERNET RESOURCES}

eBioX software: www.ebioinformatics.org/ebiox/

The Arabidopsis Information Resources website:

www.arabidopsis.org/cshl-course/7-gene_expression.html 